\title{
Keragaan Pertumbuhan Tanaman Jahe Merah (Zingiber officinale Rosc.) pada Kondisi Cekaman Kekeringan Di Provinsi Banten
}

\section{(Growth Performance of Red Ginger Plant (Zingiber officinale Rosc.) on Drought Stress Condition In Banten Province)}

\author{
Sri Lestari ${ }^{1 *}$, Yati Astuti ${ }^{1}$, Rika Jayanti Malik ${ }^{1}$, dan Eko Kardiyanto ${ }^{1}$ \\ ${ }^{1}$ Balai Pengkajian Teknologi Pertanian Banten \\ Jl. Ciptayasa KM. 01 Ciruas Serang, Banten, Indonesia \\ *Email korespondensi: sri_lestari0581@yahoo.co.id
}

Diterima 04 April 2018/Disetujui 26 Juli 2018

\begin{abstract}
This study aims to provide information about the performance of red ginger plants cultivated in drought stress conditions due to less rainfall intensity. The research was conducted in Maja sub-district of Lebak District of Banten Province from January to December 2015 with rainfall condition of $1922 \mathrm{~mm}$. The research used Randomized Block Design (RAK) which was arranged factorially with 2 (two) factors, that is fertilizer (4 treatment) and cultivation system (2 treatment) each repeated 3 times. The best technological package in vegetative phase of ginger crop aged 4 month after planting in drought stress condition is P1S2 (150\% treatment of manure on polybag planting system) for plant height parameters of $31.29 \mathrm{~cm}$ and stem diameter of $2.09 \mathrm{~cm}$. Treatment of P1S1 (150\% manure treatment on monoculture land system) yielded the highest rhizome weight (12.33 gram clump ${ }^{-1}$ ) at 6.5 month after planting. The polybag cultivation system in drought stress conditions makes crop conditions more rapidly drought when compared to cropping systems on the land.
\end{abstract}

Keywords: drought, performance, red ginger, stress

\section{ABSTRAK}

Penelitian ini bertujuan untuk memberikan informasi mengenai keragaan tanaman jahe merah yang dibudidayakan dalam kondisi cekaman kekeringan akibat intensitas curah hujan yang kurang. Penelitian dilaksanakan di kecamatan Maja Kabupaten Lebak Provinsi Banten pada bulan Januari hingga Desember 2015 dengan kondisi curah hujan pertahun 1922 mm. Penelitian menggunakan metode penelitian Rancangan Acak Kelompok (RAK) yang disusun secara faktorial dengan 2 (dua) faktor, yaitu perlakuan pupuk (4 perlakuan) dan perlakuan sistem pertanaman budidaya (2 perlakuan) masing-masing diulang sebanyak 3 kali. Paket teknologi terbaik pada fase vegetatif tanaman jahe umur 4 BST pada kondisi cekaman kekeringan yaitu pada perlakuan P1S2 (perlakuan 150\% pupuk kandang pada sistem tanam polibag) untuk parameter tinggi tanaman sebesar $31.29 \mathrm{~cm}$ dan diameter batang sebesar $2.09 \mathrm{~cm}$. Perlakuan P1S1 (perlakuan 150\% pupuk kandang pada sistem tanam monokultur lahan) menghasilkan bobot rimpang tertinggi (12.33 gram rumpun $\left.{ }^{-1}\right)$ pada umur panen 6.5 BST. Sistem pertanaman polybag pada kondisi cekaman kekeringan menjadikan kondisi tanaman lebih cepat mengalami kekeringan jika dibandingkan dengan sistem pertanaman di lahan.

Kata kunci: cekaman, jahe merah, kekeringan, keragaan

\section{PENDAHULUAN}

Potensi sumberdaya lahan pertanian di Provinsi Banten sangat besar khususnya pemanfaatan lahan pertanian. Pemanfaatan untuk tanaman hortikultura obatobatan, khususnya tanaman jahe memiliki luas panen $765,721 \mathrm{~m}^{2}$, dengan produktivitas $1.67 \mathrm{~kg} \mathrm{~m}^{-2}$ serta produksi sebesar 1,281.37 ton (BPS Banten, 2013). Kabupaten Lebak sebagai salah satu kawasan sentra produksi pertanian di Provinsi Banten dengan luas wilayah $3,426.56 \mathrm{~km}^{2}(35.46$ persen dari luas Provinsi) terdiri dari 28 Kecamatan yang meliputi 5 kelurahaan dan 320 desa. Masing-masing wilayah memiliki potensi sumberdaya biofisik dan sosial ekonomi.
Untuk luas panen tanaman jahe sebesar 246,414 $\mathrm{m}^{2}$, produksi sebesar $664,252 \mathrm{~kg}$ dengan produktivitas sebesar $2.70 \mathrm{~kg} \mathrm{~m}^{-2}$, dimana produktivitas ini lebih besar dari ratarata provinsi Banten yang sebesar $1.67 \mathrm{~kg} \mathrm{~m}^{-2}$ (BPS Banten, 2013).

Air memegang peranan penting dalam pertumbuhan dan perkembangan tanaman. Kekurangan air yang sifatnya permanen atau sementara merupakan faktor dominan yang dapat membatasi pertumbuhan tanaman budidaya dibandingkan dengan faktor lingkungan lainnya (Shao et al., 2008). Respon tanaman terhadap kondisi kekeringan tergantung pada jumlah air yang hilang, tingkat kerugian serta lamanya kekeringan (Bray, 1997). 
Menurut Karama et al. (1990), pemanfaatan lahan secara intensif untuk tanaman semusim sepanjang tahun perlu diimbangi dengan pemberian pupuk organik yang memadai untuk mempertahankan kandungan bahan organik tanah. Tanpa bahan organik, kesuburan tanah akan menurun meskipun pupuk anorganik diberikan dengan takaran tinggi. Selain itu, sistem tanam juga mempengaruhi hasil panen. Perlu dilakukan pengkajian terbih dahulu mengenai system tanam mengingat waktu panen dari tanaman jahe cukup lama yaitu 10 - 12 bulan. Mengingat akhir-akhir ini kondisi iklim tidak dapat diramalkan. Berdasarkan permasalahan tersebut di atas, perlu dilakukan pengkajian teknologi budidaya jahe yang bersifat adaptif dan spesifik lokasi. Hasil-hasil teknologi dari Balai Penelitian Tanaman Obat dan aromatik (BALITRO), perlu dikaji dalam upaya untuk memecahkan permasalahan yang dihadapi di tingkat petani untuk peningkatan produksi dan mutu hasil tanaman jahe.

Penelitian ini bertujuan untuk memberikan informasi mengenai keragaan tanaman jahe merah yang dibudidayakan dalam kondisi cekaman kekeringan akibat intensitas curah hujan yang kurang.

\section{METODE PENELITIAN}

Penelitian dilaksanakan di kecamatan Maja Kabupaten Lebak Provinsi Banten pada bulan Januari hingga Desember 2015. Bahan yang digunakan dalam penelitian ini adalah bibit jahe merah Jahira-2, pupuk Urea, KCL, SP36, pupuk cair, pupuk kandang dan obat-obatan. Untuk penyemaian bahan yang diperlukan yaitu jerami dan abu dapur. Alat yang digunakan yaitu: timbangan, cutter, ember, meteran, cangkul, polybag HDPE, selang air, alat tulis menulis, serta alat -alat lainnya yang menunjang dalam penelitian ini.

Penelitian menggunakan metode penelitian Rancangan Acak Kelompok (RAK) yang disusun secara faktorial dengan 2 (dua) faktor. Perlakuan yang diberikan dalam penelitian ini adalah kombinasi pupuk dan sistem pertanaman budidaya.

a. Faktor pertama, penggunaan kombinasi pupuk (P) terdiri dari :

(P1). $150 \%$ Pupuk kandang $\left(0.75 \mathrm{~kg} \mathrm{lubang}^{-1}\right)$

(P2). $100 \%$ Pupuk kandang $\left(0.5 \mathrm{~kg} \mathrm{lubang}^{-1}\right)+100 \%$ Urea $\left(300 \mathrm{~kg} \mathrm{Ha}^{-1}\right)+100 \% \mathrm{KCl}\left(200 \mathrm{~kg} \mathrm{Ha}^{-1}\right)+$ $100 \%$ SP36 $\left(200 \mathrm{~kg} \mathrm{Ha}^{-1}\right)$

(P3). $100 \%$ Pupuk kandang $\left(0.5 \mathrm{~kg} \mathrm{lubang}^{-1}\right)+50 \%$ Urea $\left(150 \mathrm{~kg} \mathrm{Ha}^{-1}\right)+50 \% \mathrm{KCl}\left(100 \mathrm{~kg} \mathrm{Ha}^{-1}\right)+$ $50 \%$ SP36 $\left(100 \mathrm{~kg} \mathrm{Ha}^{-1}\right)$

(P4). $100 \%$ pupuk kandang $\left(0.5 \mathrm{~kg} \mathrm{lubang}^{-1}\right)+50 \%$ Urea $\left(150 \mathrm{~kg} \mathrm{Ha}^{-1}\right)+50 \% \mathrm{KCl}\left(100 \mathrm{~kg} \mathrm{Ha}^{-1}\right)+$ $50 \%$ SP36 $\left(100 \mathrm{~kg} \mathrm{Ha}^{-1}\right)+$ Pupuk Organik Cair (POC)

b. Faktor kedua, penggunaan sistem pertanaman (S), terdiri dari :

(S1). Sistem monokultur di lahan

(S2). Sistem Polibag
Masing-masing perlakuan diulang sebanyak 3 kali sehingga didapatkan 24 satuan percobaan. Masing-masing plot percobaan terdiri dari 200 tanaman jahe. Kemudian ditentukan 10 tanaman sample yang akan digunakan untuk pengamatan. Kesepuluh sample dipilih secara acak. Semua perlakuan diberikan sebagai pupuk dasar, kecuali Urea diberikan sebanyak 3 kali yaitu pada umur 1, 2 dan 3 BST masing-masing $1 / 3$ dosis serta POC (Pupuk Organik Cair) diberikan sesuai dosis dan aturan pakai yang dianjurkan. Jarak tanaman optimal yang digunakan adalah $60 \mathrm{~cm}$ x 40 $\mathrm{cm}$. Jarak tanam ini dipergunakan pada sistem pertanaman monokultur.

Parameter yang diamati meliputi tinggi tanaman, jumlah daun, jumlah anakan, diameter batang serta bobot rimpang. Semua data kecuali bobot rimpang diambil pada umur 1 BST (kecuali parameter diameter batang), 2 BST, 3 BST serta 4 BST. Data bobot rimpang diambil pada saat tanaman berumur 6.5 BST. Data yang diperoleh dianalisis dengan sidik ragam dan apabila sidik ragam menunjukkan perbedaan yang nyata dilakukan uji lanjut dengan uji Duncan Multiple Range Test (DMRT) pada taraf 5\%.

\section{HASIL DAN PEMBAHASAN}

\section{Kondisi Tanah}

Berdasarkan klasifikasi tanah, tanah yang digunakan yaitu ultisol, pada umumnya ultisol berwarna kuning kecoklatan hingga merah. Pada klasifikasi lama menurut Soepraptohardjo (1961), ultisol diklasifikasikan sebagai Podsolik Merah Kuning (PMK). Reaksi tanah ultisol pada umumnya masam hingga sangat masam ( $\mathrm{pH} 5-3,10)$ (Prasetyo et al., 2005). Menurut Prasetyo et al. (2006), kendala pemanfaatan tanah ultisol untuk pengembangan pertanian adalah kemasaman dan kejenuhan Al yang tinggi, kandungan hara dan bahan organik rendah dan tanah peka terhadap erosi. Berbagai kendala tersebut dapat diatasi dengan penerapan teknologi seperti pengapuran, pemupukan, dan pengelolaan bahan organik.

\section{Kondisi Cuaca Di Lokasi Penelitian}

Menurut Rostiana et al., persyaratan tumbuh tanaman jahe yaitu pada curah hujan per tahun $2.500-4.000 \mathrm{~mm}$, jumlah bulan basah (> $\left.100 \mathrm{~mm} \mathrm{bulan}^{-1}\right) 7-9$ bulan tahun ${ }^{-1}$. Sesuai data curah hujan di kabupaten Lebak pada tahun 2015, curah hujan per tahun hanya $1922 \mathrm{~mm}$ dan jumlah hari hujan sebanyak 80 hari per tahun (2.5 bulan) (BPP Kecamatan Rangkasbitung, 2015). Sehingga memang pada tahun 2015, cuaca tidak mendukung untuk pertanaman jahe.

\section{Keragaan Tanaman Jahe Pada Umur 1-4 Bulan Setelah Tanam (BST)}

Hasil analisis sidik ragam terhadap tinggi tanaman, jumlah daun, jumlah anakan serta diameter batang ditunjukkan oleh Tabel 1. 
Tabel 1. Keragaan tanaman jahe pada umur 1-4 BST

\begin{tabular}{|c|c|c|c|c|c|c|c|c|c|c|c|c|c|c|c|c|}
\hline \multirow{3}{*}{ Perlakuan } & \multicolumn{4}{|c|}{ Tinggi Tanaman $(\mathrm{cm})$} & \multirow{2}{*}{\multicolumn{4}{|c|}{$\frac{\text { Jumlah Daun (helai) }}{\text { Umur }}$}} & \multirow{2}{*}{\multicolumn{4}{|c|}{$\begin{array}{c}\text { Jumlah Anakan (buah) } \\
\text { Umur }\end{array}$}} & \multirow{2}{*}{\multicolumn{4}{|c|}{$\frac{\text { Diameter Batang }(\mathrm{cm})}{\text { Umur }}$}} \\
\hline & \multicolumn{4}{|c|}{ Umur } & & & & & & & & & & & & \\
\hline & $\begin{array}{c}1 \\
\text { BST }\end{array}$ & $\begin{array}{c}2 \\
\text { BST }\end{array}$ & $3 \mathrm{BST}$ & $\begin{array}{c}4 \\
\text { BST }\end{array}$ & & $4 \mathrm{BST}$ & $\begin{array}{c}1 \\
\text { BST }\end{array}$ & $\begin{array}{c}2 \\
\text { BST }\end{array}$ & $\begin{array}{c}3 \\
\text { BST }\end{array}$ & $\begin{array}{c}4 \\
\text { BST }\end{array}$ & $\begin{array}{c}1 \\
\text { BST }\end{array}$ & $\begin{array}{c}2 \\
\text { BST }\end{array}$ & $\begin{array}{c}3 \\
\text { BST }\end{array}$ & $\begin{array}{c}4 \\
\text { BST }\end{array}$ \\
\hline P1S1 & $11.4^{\mathrm{b}}$ & $17.7^{\mathrm{b}}$ & $21.9^{\text {cde }}$ & $25.9^{\mathrm{bc}}$ & $5.7^{\mathrm{a}}$ & $9.3^{\mathrm{a}}$ & $14.2^{\mathrm{a}}$ & $29.5^{\mathrm{ab}}$ & $0.4^{\mathrm{b}}$ & $1.1^{\mathrm{tn}}$ & $1.9^{\mathrm{bc}}$ & $3.1^{\mathrm{b}}$ & - & $1.4^{\mathrm{b}}$ & $1.7^{\mathrm{abc}}$ & $1.9^{\mathrm{abc}}$ \\
\hline $\mathrm{P} 2 \mathrm{~S} 1$ & $11.6^{\mathrm{ab}}$ & $19.6^{\mathrm{ab}}$ & $23.8^{\mathrm{bcd}}$ & $26.2^{\mathrm{bc}}$ & $5.4^{\mathrm{ab}}$ & $7.9^{\mathrm{ab}}$ & $12.6^{\mathrm{ab}}$ & $29.5^{\mathrm{ab}}$ & $0.5^{\mathrm{b}}$ & $0.9^{\text {tn }}$ & $2.6^{\mathrm{b}}$ & $3.6^{\mathrm{ab}}$ & - & $1.1^{\mathrm{c}}$ & $1.4^{\mathrm{c}}$ & $1.6^{\mathrm{d}}$ \\
\hline P3S1 & $10.6^{\mathrm{bc}}$ & $16.5^{\mathrm{b}}$ & $21.0^{\mathrm{de}}$ & $24.5^{\mathrm{bc}}$ & $4.3^{\mathrm{cd}}$ & $6.6^{\mathrm{bc}}$ & $10.3^{\mathrm{b}}$ & $30.3^{\mathrm{ab}}$ & $0.7^{\mathrm{ab}}$ & $1.0^{\mathrm{tn}}$ & $1.9^{\mathrm{bc}}$ & $3.2^{\mathrm{b}}$ & - & $1.4^{\mathrm{ab}}$ & $1.7^{\mathrm{ab}}$ & $1.7^{\mathrm{cd}}$ \\
\hline P4S1 & $8.2^{\mathrm{c}}$ & $12.4^{\mathrm{c}}$ & $17.9^{\mathrm{e}}$ & $22.3^{\mathrm{c}}$ & $4.3^{\mathrm{cd}}$ & $6.8^{\mathrm{bc}}$ & $11.3^{\mathrm{ab}}$ & $16.8^{\mathrm{c}}$ & $0.6^{\mathrm{b}}$ & $0.8^{\mathrm{tn}}$ & $1.1^{\mathrm{c}}$ & $1.5^{\mathrm{c}}$ & - & $1.4^{\mathrm{ab}}$ & $1.5^{\mathrm{bc}}$ & $1.7^{\mathrm{bcd}}$ \\
\hline $\mathrm{P} 1 \mathrm{~S} 2$ & $14.1^{\mathrm{a}}$ & $22.5^{\mathrm{a}}$ & $30.9^{\mathrm{a}}$ & $31.3^{\mathrm{a}}$ & $4.7^{\mathrm{bcd}}$ & $6.6^{\mathrm{bc}}$ & $12.4^{\mathrm{ab}}$ & $26.3^{\mathrm{abc}}$ & $0.4^{\mathrm{b}}$ & $0.8^{\text {tn }}$ & $1.9^{\mathrm{bc}}$ & $2.9^{b}$ & - & $1.4^{\mathrm{ab}}$ & $1.8^{\mathrm{ab}}$ & $2.1^{\mathrm{a}}$ \\
\hline $\mathrm{P} 2 \mathrm{~S} 2$ & $12.2^{\mathrm{ab}}$ & $19.2^{\mathrm{ab}}$ & $28.0^{\mathrm{ab}}$ & $30.9^{\mathrm{a}}$ & $5.3^{\mathrm{ab}}$ & $8.5^{\mathrm{a}}$ & $14.0^{\mathrm{a}}$ & $33.2^{\mathrm{a}}$ & $0.6^{\mathrm{b}}$ & $1.3^{\text {tn }}$ & $2.6^{\mathrm{b}}$ & $4.5^{\mathrm{a}}$ & - & $1.4^{\mathrm{ab}}$ & $1.7^{\mathrm{abc}}$ & $1.9^{\mathrm{a}}$ \\
\hline P3S2 & $12.4^{\mathrm{ab}}$ & $20.5^{\mathrm{ab}}$ & $27.2^{\mathrm{ab}}$ & $31.3^{\mathrm{a}}$ & $4.9^{\mathrm{abc}}$ & $8.4^{\mathrm{a}}$ & $13.9^{\mathrm{a}}$ & $36.2^{\mathrm{a}}$ & $1.0^{\mathrm{a}}$ & $1.3^{\text {tn }}$ & $3.5^{\mathrm{a}}$ & $4.5^{\mathrm{a}}$ & - & $1.4^{\mathrm{ab}}$ & $1.8^{\mathrm{a}}$ & $2.1^{\mathrm{a}}$ \\
\hline $\mathrm{P} 4 \mathrm{~S} 2$ & $11.1^{\mathrm{b}}$ & $19.0^{\mathrm{ab}}$ & $25.9^{\mathrm{bc}}$ & $28.8^{\mathrm{ab}}$ & $4.0^{\mathrm{d}}$ & $5.9^{\mathrm{c}}$ & $11.4^{\mathrm{ab}}$ & $22.8^{\mathrm{bc}}$ & $0.8^{\mathrm{ab}}$ & $1.2^{\mathrm{tn}}$ & $2.2^{\mathrm{b}}$ & $2.8^{\mathrm{b}}$ & - & $1.6^{\mathrm{a}}$ & $1.7^{\mathrm{abc}}$ & $1.9^{\mathrm{ab}}$ \\
\hline
\end{tabular}

Keterangan: Angka yang diikuti oleh huruf yang sama pada masing-masing variabel menunjukkan tidak berbeda nyata berdasarkan uji DMRT pada taraf $\alpha=0.05$.

Pada tanaman jahe umur 1 BST, tinggi tanaman tertinggi yaitu pada perlakuan P1S2 dan terendah pada perlakuan P4S1. Diduga karena pada perlakuan P1S1 menggunakan pupuk organik (pupuk kandang) yang lebih banyak bila dibandingkan dengan perlakuan P4S1. Penggunaan setengah dosis pupuk kimia dan pupuk organik cair ternyata tidak membuat tanaman jahe menjadi lebih baik pertumbuhannya.

Bahan organik mempunyai peranan sangat penting dalam meningkatkan kesuburan tanah, baik terhadap pertumbuhan maupun hasil tanaman. Pada penelitian ini, dosis pupuk kandang tertinggi yaitu pada P1 sebesar $0.75 \mathrm{~kg}$ ${ }^{-1}$ lubang (31.25 ton/Ha). Jenis pupuk kandang yang dipergunakan adalah kotoran sapi yang dicampur dengan sekam. Menurut Undang et al. (1996) dalam Juarsah (2014), bahwa hasil penelitian menjelaskan pemberian pupuk kandang $5 \mathrm{t} \mathrm{ha}^{-1}$ atau lebih telah dapat meningkatkan kandungan $\mathrm{C}$-organik. Tinggi tanaman tertinggi yaitu pada perlakuan P1S2. Hal ini diduga disebabkan karena dosis pupuk kandang yang diberikan yaitu $0.75 \mathrm{~kg}$ lubang $^{-1}$. Dengan sistem tanam polibag menyebabkan pupuk lebih terkonsentrasi pada satu rumpun tanaman jahe. Bahan organik berperan meningkatkan daya menahan air (water holding capacity), memperbaiki struktur tanah menjadi gembur, mencegah pengerasan tanah, serta menyangga reaksi tanah dari kemasaman, kebasaan, dan salinitas (Tisdale et al., 1993; Dobermann dan Fairhurst 2000).

Pada usia tanaman 2 BST, 3 BST dan 4 BST untuk parameter tinggi tanaman, jumlah daun dan diameter batang jahe menunjukkan hasil perbedaan yang nyata. Pada parameter jumlah anakan menunjukkan hasil yang tidak berbeda nyata. Tinggi tanaman jahe tertinggi yaitu pada perlakuan P1S2 namun tidak berbeda nyata dengan perlakuan pupuk yang lain pada sistem tanam polibag. Pada perlakuan pupuk P2S1 menunjukkan hasil yang tidak berbeda nyata dengan keempat perlakuan pupuk pada polibag. Hal ini disebabkan karena dosis pupuk pada perlakuan P2S1 merupakan dosis pupuk standar sesuai SOP budidaya tanaman jahe.
Menurut Prasetyo et al. (2006), pertumbuhan tanaman jahe merah terus meningkat dari 7 minggu setelah tanam sampai tanaman berumur 19 minggu. Pada umumnya pertumbuhan tanaman jahe merah pada saat minggu 7-19 setelah tanam relatif seragam. Hal ini diduga pada saat itu tanaman jahe merah masih mengalami satu fase pertumbuhan yaitu fase pertumbuhan vegetatif yang cepat. Sitompul dan Guritno (1995), menjelaskan bahwa pada awalnya pertumbuhan vegetatif berjalan lambat, kemudian cepat (masa pertumbuhan vegetatif cepat) dan akhirnya perlahan sampai konstan (memasuki fase generatif.

Pada usia tanaman 3 BST, dapat dilihat bahwa pertumbuhan tanaman jahe pada perlakuan sistem tanam menunjukkan hasil yang berbeda nyata. Akan tetapi perlakuan dosis pemupukan pada sistem tanam yang sama menunjukkan hasil yang tidak berbeda nyata. Menurut Yusron et al. (2012), penurunan dosis pupuk sampai 50\% dari dosis anjuran tidak mengurangi tinggi tanaman jahe pada beberapa aksesi tanaman jahe. Perlakuan sistem tanam dengan menggunakan polibag cenderung menghasilkan tinggi tanaman yang relatif lebih tinggi dibandingkan dengan sistem tanam pada lahan. Hal ini diduga karena pada sistem tanam polibag, tanaman jahe tidak mengalami kompetisi unsur hara.

Diameter batang tanaman jahe pada umur 4 BST menghasilkan diameter terbesar pada perlakuan P1S2 yaitu sebesar 2,1 cm (sistem tanam polibag). Pada sistem tanam di lahan, diameter tanaman terbesar pada perlakuan P1S1 yaitu sebesar $1,9 \mathrm{~cm}$ dan tidak berbeda nyata dengan diameter batang pada perlakuan P1S2. Diameter batang merupakan parameter yang berkorelasi positif dengan ukuran rimpang, dimana makin besar ukuran diameter batang, rimpang yang terbentuk semakin besar (Yusron et al., 2012).

\section{Hasil Panen Rimpang Jahe}

Air bagi tanaman sangat berperan penting. Air berfungsi sebagai 1). Pelarut dan medium reaksi kimia, 2). Medium transpor, 3). Medium untuk memberikan turgor pada sel, 4). Hidrasi dan netralisis muatan pada molekul- 
molekul koloid, 5). Bahan baku untuk fotosintesis, dan 6). Transpirasi untuk mendinginkan tanaman (Gardner et al., 1991). Khaerana et al (2008) juga menyatakan bahwa tanaman yang mengalami cekaman kekeringan akan berusaha melakukan perubahan-perubahan fisiologi sebagai bentuk adaptasinya. Salah satu bentuk adaptasi tersebut adalah kemampuan tanaman untuk mempertahankan tekanan turgor atau penyesuaian osmotik.

Pada saat tanaman jahe berumur 6.5 BST, tanaman jahe mengalami senescence. Kondisi fisik tanaman jahe mengalami kekeringan dari bagian daun, batang serta akar. Data hasil panen rimpang jahe pada umur 6.5 BST ditunjukkan pada Gambar 1.

Dari hasil sidik ragam menunjukkan bahwa hasil panen rimpang jahe menunjukkan beda nyata pada tingkat kepercayaan 5\%. Hasil panen rimpang pada umur 6.5 BST rata-rata 0.67 - 12.33 gram. Pada kondisi normal, tanaman jahe merah yang dipanen pada umur 10 bulan dapat menghasilkan bobot rimpang 22 ton $\mathrm{ha}^{-1}$ atau 528 gram rumpun $^{-1}$ (Rostiana et al., 2016 ).

Kondisi lingkungan yang kering dan kurang air menyebabkan pertumbuhan rimpang terganggu. Bobot rimpang tertinggi yaitu pada perlakuan P1S1 dan terendah pada perlakuan P1S2. Perlakuan dengan sistem tanam pada lahan menghasilkan bobot rimpang yang lebih tinggi bila dibandingkan dengan sistem tanam pada polibag. Hal ini diduga karena pada sistem tanam di lahan, walaupun tanaman jahe kekurangan air tapi tanah masih dapat menyediakan kelembaban sehingga kondisi rimpang masih banyak yang segar. Akan tetapi, kondisi tanah pada sistem tanam polibag sangat mengalami kekeringan sehingga menyebabkan rimpang jahe juga mengering dikarenakan suhu udara di dalam polibag sangat tinggi dan kondisi tanah yang kering.

Menurut hasil penelitian Devy dan Newfetrias (2013), kondisi cekaman air mempengaruhi bobot kering rimpang jahe. Data dapat dilihat pada Tabel 2. Menurut Islami dan Utomo (1995), hasil panen dapat sangat menurun pada kekeringan karena cekaman air menurunkan aktifitas fotosintesis melalui 3 mekanisme, yaitu 1). Luas permukaan fotosintesis, 2). Menutupnya stomata, dan 3). Berkurangnya aktifitas protoplasma yang telah mengalami dehidrasi.

Devy et al. (2013), masalah umum yang menjadi kendala peningkatan produktivitas di lahan kering antara lain kurangnya kadar air tanah akibat curah hujan yang relatif rendah. Hal ini berpotensi mengakibatkan cekaman kekeringan pada tanaman. Khaerana et al. (2008) juga mengatakan bahwa penurunan produktivitas tanaman akibat cekaman kekeringan juga ditunjukkan pada tanaman temulawak.

Pertumbuhan dan perkembangan tanaman jahe pada lokasi penelitian memang tidak maksimal dikarenakan kondisi lingkungan yang terlalu panas (tidak ada naungan). Menurut Gardner et al. (1991) bahwa cahaya yang terlalu tinggi dapat menekan kerja auksin dan sebaliknya cahaya yang rendah memacu kerja auksin. Tertekannya kerja auksin dapat mengurangi tinggi tanaman.

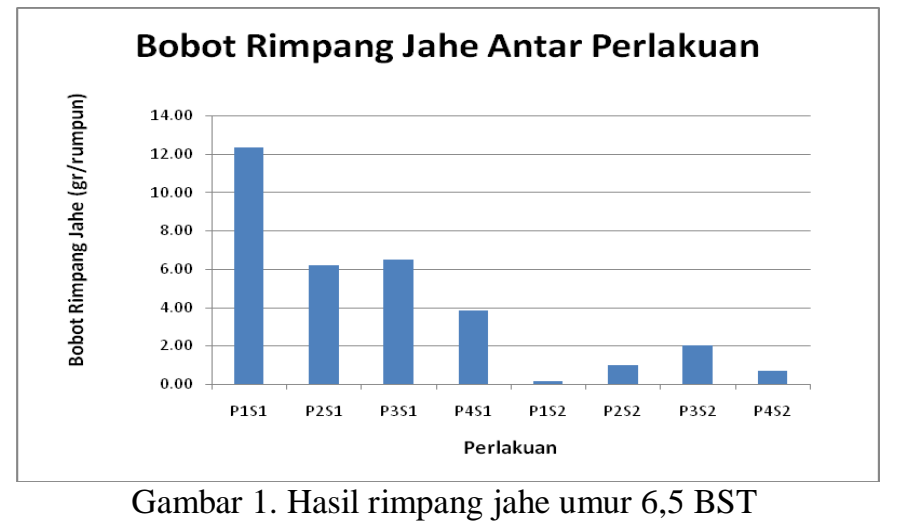

Tabel 2. Pengaruh cekaman air terhadap bobot rimpang jahe

\begin{tabular}{cc}
$\begin{array}{c}\text { Periode Cekaman Kekeringan } \\
\text { (Minggu Sebelum Panen) }\end{array}$ & $\begin{array}{c}\text { Rataan } \\
\text { (gram/rumpun) }\end{array}$ \\
\hline 0 & $14.97 \mathrm{a}$ \\
2 & $13.83 \mathrm{a}$ \\
4 & $8.53 \mathrm{~b}$ \\
6 & $8.01 \mathrm{~b}$
\end{tabular}

Keterangan: Nilai rataan pada kolom yang sama yang diikuti oleh huruf yang sama tidak berbeda nyata berdasarkan Uji Duncan pada $\alpha=5 \%$. 
Menurut Januwati dan Muhammad (1997), naungan dapat menurunkan suhu udara di sekitar tanaman jahe sehingga mengurangi laju respirasi. Efek penggunaan naungan dapat mengurangi cahaya yang diterirna tanaman, menurunkan suhu udara dan mempertahankan kelembaban tanah (Magfoer dan Koesriharti, 1998). Penelitian mengenai pengaruh naungan terhadap jahe, paprika dan manggis telah banyak dilakukan. Januwati et al. (2000) mengemukakan bahwa naungan yang cocok untuk tanaman jahe di bawah tegakan pohon kelapa berkisar 40 - 50\%. Penggunaan naungan paranet dengan intensitas naungan $25 \%$ dan $50 \%$ lebih mempengaruhi pertumbuhan dan hasil jahe merah sedangkan jahe ernprit tumbuh baik pada intensitas naungan 50\% (Entang et al., 2002).

\section{KESIMPULAN}

Paket teknologi terbaik pada fase vegetatif tanaman jahe umur 4 BST pada kondisi cekaman kekeringan yaitu pada perlakuan P1S2 perlakuan $150 \%$ pupuk kandang pada sistem tanam polibag) untuk parameter tinggi tanaman sebesar $31.29 \mathrm{~cm}$ dan diameter batang sebesar $2.09 \mathrm{~cm}$. Perlakuan P1S1 (perlakuan $150 \%$ pupuk kandang pada sistem tanam monokultur lahan) menghasilkan bobot rimpang tertinggi (12.33 gram rumpun ${ }^{-1}$ ) pada umur panen 6.5 BST. Sistem pertanaman polibag pada kondisi cekaman kekeringan menjadikan kondisi tanaman lebih cepat mengalami kekeringan jika dibandingkan dengan sistem pertanaman di lahan.

\section{UCAPAN TERIMA KASIH}

Ucapan terima kasih ditujukan kepada Bapak Dr. Ir. Muchamad Yusron, M.Phil atas arahan dan bimbingannya dalam pelaksanaan penelitian ini. Terima kasih pula disampaikan kepada Ibu Rina Sinta Wati, SP, M.Si atas bantuan pemikiran serta tenaganya serta Bapak Suryadi selaku teknisi yang membantu pelaksanaan penelitian ini. Sumber dana penelitian berasal dari dana APBN Badan Litbang Kementerian Pertanian.

\section{DAFTAR PUSTAKA}

[BPS] Badan Pusat Statistik Provinsi Banten. 2013. Produksi Tanaman Hortikultura (Tanaman Sayuran, Buahbuahan, Hias dan Obat-obatan) Provinsi Banten 2012. Badan Pusat Statistik Provinsi Banten.

BPP Kecamatan Rangkasbitung. 2015. Program Kecamatan Rangkasbitung Kabupaten Lebak.

Bray, E.A. 1997. Plant Responses to Water Deficit. Trends In Plant Science. 2 (2):48-54. http://www.sciencedirect.com/science/article/pii/S13 60138597825629. [Diakses tanggal 23 November 2017].

Devy, L., W. Newfetrias. 2013. Pertumbuhan, kuantitas dan kualitas rimpang jahe (Zingiber officinale Roscoe) pada cekaman kekeringan di bawah naungan. Jurnal Sains dan Teknologi Indonesia. 14(3):216-220.

Dobermann, A., T. Fairhurst. 2000. Rice nutrient disorders and nutrient management. Potash \& Phosphate Institute (PPI), Potash \& Phosphate Institute of Canada (PPIC) and IRRI. hal. 2- 37.

Entang, I.S., Fahrurrozie, E. Fatwa. 2002. Respon dan klon jahe terhadap berbagai intensitas cahaya. Prosiding Seminar Nasional BKS hlm. 180-192. PTAL. Fakultas Pertanian USU, Medan

Gardner, F.P., R.B. Pearce, R.L. Mitchell. 1991. Physiologi of Crop Plants (Fisiologi Tanaman Budidaya, alih bahasa: Herawati Susilo). Universitas Indonesia Press, Jakarta.

Islami, T., W.H. Utomo. 1995. Hubungan Air, Tanah, dan Tanaman. IKIP Semarang Press, Semarang.

Januwati, M., Muhammad. 1997. Peranan lingkungan fisik terhadap produksi. Balai Penelitian Tanaman Rempah dan Obat, Bogor.

Januwati, M.N., Heryana, H. Luntungan. 2000. Pertumbuhan dan produksi jahe gajah (Zingiber officinale var. Officinale Rosc.) sebagai tanaman sela diantara tegakan pohon kelapa (Cocos nucifera L.). Habitat 2. (3): $65-70$.

Juarsah, I. 2014. Pemanfaatan pupuk organik untuk pertanian organik dan lingkungan berkelanjutan. Prosiding Seminar Nasional Pertanian Organik. Bogor, 18-19 Juni 2014.

Karama, A.S., A.R. Marzuki, I. Marwan. 1990. Penggunaan pupuk organik pada tanaman pangan. Prosiding Lokakarya Nasional Efisiensi Penggunaan Pupuk Pusat Penelitian Tanah dan Agroklimat. Hlm. 395425.

Khaerana, M. Ghulamahdi, E.D. Purwakusumah. 2008. Pengaruh cekaman kekeringan dan umur panen terhadap pertumbuhan dan kandungan xanthorrhizal temulawak (Curcuma xanthorrhiza roxb.) Bul. Agron. 36: 241-247.

Maghfoer, M.D., Koesriharti. 1998. Rekayasa teknologi penallngan dalam sistem budidaya tanaman paprika (Capsicwrt annuum L.). Jurnal Penelitian Ilmu-ilmu Teknik (Engineering). 10( 1 ):89-95.

Prasetyo, H. Ulianna, B. Gonggo. 2006. Pola pertumbuhan tanaman jahe merah dengan intensitas naungan dan dosis pupuk $\mathrm{KCl}$ pada sistem wanafarma di perkebunan karet. Jurnal Akta Agrosia. 9(1):19-24. 
Prasetyo, B.H., D.A. Suridikarta. 2006. Karakteristi, potensi, dan teknologi pengelolaan tanah ultisol untuk pengembangan pertanian lahan kering di Indonesia. Jurnal Litbang Pertanian. 25(2):39-46.

Rostiana, O., N. Bermawie, dan M. Rahardjo. 2016. Standar Prosedur Operasional Budidaya Jahe. www.balittro.litbang.pertanian.go.id [diakses tanggal 11 Januari 2016].

Shao, H.B., L.Y. Chu, C.A. Jaleel, C.X. Zhao. 2008. Water Deficit Stress Induced Anatomical Changes In Higher Plants. Comptes Rendus Biologies. 331(3):215-225. https://www.sciencedirect.com/science/article/pii/S16 31069108000048. [diakses tanggal 23 November 2017].
Soepraptohardjo, M. 1961. Tanah merah di Indonesia. Contr. Gen. Agric. Res. Sta. No. 161. Bogor.

Tisdale, S.L., W.L. Nelson, J.D. Beaton, J.L. Halvlin. 1993. Soil fertility and fertilizers. Fifth Edition. Macmillan Pub. Co. New York, Canada, Toronto, Singapore, Sidney. hal. 462-607.

Sitompul, S.M., B. Guritno. 1995. Analisis Perturnbuhan Tanaman. Gadjah Mada University Press, Yogyakarta.

Yusron M, C. Syukur, O. Trisilawati. 2012. Respon Lima Aksesi Jahe putih Kecil (Zingiber officinale var. Amarum) terhadap Pemupukan. Jurnal Penelitian Tanaman Industri. 18(2):66-73. 